\title{
A Nova Música Paraense e a busca pelo "sotaque perdido": diferentes performances, velhas narrativas, antigos dilemas
}

\section{The new Paraense Music and the search for the "lost accent": different performances, ancien narratives, old dilemmas}

Andrey Faro de Lima Professor da Escola de Aplicação da Universidade Federal do Pará (EAUFPA) Doutor em Ciências Sociais/Antropologia - PPGS/UFPA farolima@yahoo.com.br 
Resumo: Sobretudo a partir da virada deste último século, produtores, músicos e gestores paraenses e de outros estados e regiões tem se articulado em torno da divulgação, em âmbito nacional, do que ficou conhecido como a Nova Música Paraense. Esta, por sua vez, ancorada em três eixos estéticos: a influência da música caribenha e/ou latino-americana; a atualização do brega, com suas variantes e ramificações; e a utilização de tecnologias e recursos contemporâneos relativos aos processos de produção, reprodução, circulação e consumo musical. Associam-se ainda uma série de representações que darão significação ética à conjunção destes: condição periférica, espontaneidade, criatividade, exotismo, dentre outras correlações. Evidentemente, todas estas articulações não são aleatórias, ou mesmo simples decorrência de um vanguardismo idiossincrático, pois vêm se coadunar a uma espécie de deslocamento, que redireciona a importância, a legitimidade e o potencial narrativo dos tradicionais discursos acerca da música popular, com toda a sua ênfase nas dimensões arcaicas e rurais, para outra ideia: agora são as nuances a partir das quais as manifestações urbanas periféricas articulam elementos tradicionais e modernos, locais e globais que passam a retroalimentar e representar as expressões populares. Destarte, levando-se em conta tais considerações, procurei então entender como se desenvolveu este deslocamento e como foi apropriado e reproduzido em âmbito regional/paraense. A partir de entrevistas junto a personagens reconhecidamente envolvidos e/ou influentes nesse processo; e tomando como referência a dimensão retórico-performática das elaborações identitárias, buscou-se compreender como foram tecidas as mais recentes narrativas em torno da, hegemonicamente divulgada, Nova Música Paraense. As experimentações presentes nos trabalhos de grande parte dos artistas identificados com este momento refletem a busca pela ideia de uma sensibilidade associada ao domínio fronteiriço e periférico em um contexto relacional e contrastivo notadamente colonial.

Palavras-chave: Música Popular; Narrativas; Guitarrada; Brega; Terruá Pará.

\begin{abstract}
Especially since the turn of this century, producers, musicians and managers from Pará and other states and regions have articulated around the dissemination, at a national level, than it became known as the New Paraense Music. This, in turn, anchored in three aesthetic axes: the influence of the Caribbean and/or Latin American music; the revival of the brega, with its variants and ramifications; and the use of contemporary technologies and resources related to the production processes, reproduction, circulation and musical consumption. A series of representations are added that will give ethical significance to the conjunction of these: peripheral condition, spontaneity, creativity, exoticism, among other correlations. Of course, all these articulations are not random, or even a simple idiosyncratic vanguardism, because it indicates a kind of displacement, which redirects the importance, legitimacy and narrative potential of traditional discourses about popular music, with all its emphasis on the archaic dimensions and rural, for another idea: Now are the nuances from which peripheral urban manifestations articulate traditional and modern, local and global elements that will feed back and represent popular expressions. Thus, through these considerations, I try to understand how this displacement has developed and how it was appropriate and reproduced at the regional / Paraense level. From interviews with people involved and/or influential in this process; And taking as a reference the discursive-performance dimension of the identiry elaborations, it was sought to understand how the most recent
\end{abstract}


A Nova Música Paraense e a busca pelo "sotaque perdido": diferentes performances, velhas narrativas, antigos dilemas

narratives about the new music from Pará. The present experiments in the works of most of the artists identified with this moment reflect the search for the idea of a sensitivity associated with the border and peripheral domain in a relational and contrastive context, especially colonial.

Keywords: Popular Music; Narratives; Guitarrada; Brega; Terruá Pará. 
Em 30 de dezembro de 2011, o conhecido produtor, jornalista e escritor Nelson Motta dedicou a coluna semanal que mantém desde 2009 no Jornal da Globo (telejornal noturno da Rede Globo) à apresentação de um prospecto dos acontecimentos mais importantes ocorridos no cenário da música mundial e nacional durante o ano que findava. A coluna, excepcionalmente denominada Retrospectiva de Nelson Motta, discorreu acerca do suposto crescimento econômico do Brasil, que teria possibilitado a inserção do país no circuito das grandes turnês internacionais. Apôs ainda sobre a projeção de novos artistas reconhecidos como "as mais recentes revelações" da música brasileira e anunciou alguns dos principais eventos e novidades previstos para o ano de 2012. A té então, nada que surpreendesse os que, costumeiramente, já acompanhavam as suas matérias (não somente no referido telejornal), mas antes de se despedir dos telespectadores o colunista sentenciou, como um prenúncio, algo que talvez tenha chamado atenção dos mais desavisados: "Na música brasileira, se preparem para dançar, porque a grande sensação vai ser o novo som de Belém do Pará. Feliz 2012!” (MOTTA, 2011).

Nelson Motta não teceu maiores comentários sobre este "novo som", apenas manteve certo clima de expectativa. À primeira vista, soaria mais um artifício retórico jornalístico qualquer, se não fosse por um detalhe: $O$ colunista em questão é publicamente reconhecido como um suposto arauto da música brasileira, o que leva a crer que sua sentença constituiu mais uma condução ao que se deveria atentar, do que uma predição de algo que, invariavelmente, ocorreria.

De todo modo, o "novo som” ao qual Nelson Motta se referiu não chegou aos seus ouvidos por mero acaso. Desde pelo menos os primeiros anos deste atual milênio, produtores, músicos e gestores paraenses e de outras regiões tem se articulado em torno da divulgação, em âmbito nacional, do que ficou conhecido como a Nova Música Paraense. ${ }^{1}$ Esta, por sua vez, ancorada, sobretudo, em três eixos estéticos: a influência da música caribenha e/ou latino-americana; as referências ao carimbó e ao brega, com suas variantes e ramificações; e a utilização de tecnologias e recursos contemporâneos relativos aos processos de produção, reprodução, circulação e consumo musical. Associam-se ainda uma série de representações que darão significação ética à conjunção destes três eixos: condição periférica, espontaneidade, criatividade, exotismo, dentre outras correlações. 
Entrementes, surgiram novos artistas e bandas identificados com este momento, concomitante o reaparecimento de antigos músicos populares agora reconhecidos e legitimados como tradicionais representantes de uma musicalidade presumível e caracteristicamente paraense.

Associado a estes projetos, a ênfase na dimensão criativa e original passou a ser comumente reproduzida por diversos meios comunicacionais, em textos jornalísticos, propagandas e programas televisivos e radiofônicos, publicações eletrônicas e revistas. A música e as sociabilidades reconhecidas como periféricas passaram para a ordem do dia. O brega, por meio de suas contemporâneas vertentes - tecnobrega, melody, eletromelody -, tornou-se cada vez mais um dos principais símbolos de uma vitalidade musical. Conjuntamente, a lambada, outro ritmo associado ao domínio das camadas populares, foi também incluída no bojo das narrativas que emergiam. Artistas até então desconhecidos do grande público - Vieira, Aldo Sena, Alípio Martins, Manezinho do Sax - transformaram-se em referências desta suposta retomada.

Evidentemente, todas estas articulações não são aleatórias, ou mesmo simples decorrência de um vanguardismo idiossincrático, pois vêm se coadunar a uma espécie de deslocamento, que redireciona a importância, a legitimidade e o potencial narrativo do que se entenderia por música popular, com toda a sua ênfase nas dimensões arcaicas e rurais, para outra ideia: agora são as nuances a partir das quais as manifestações urbanas entendidas como periféricas articulam elementos tradicionais e modernos, locais e globais, que retroalimentam a mesma indústria do exotismo que se faz recorrente, e que de modo algum se desenvolve por mero acaso ou altruísmo artístico. A partir de entrevistas junto a personagens reconhecidamente envolvidos e/ou influentes nesse processo; e tomando como referência a dimensão retórico-performática das elaborações identitárias, buscou-se compreender como foram tecidas as mais recentes narrativas em torno da, hegemonicamente divulgada, nova músicaparaense.

\section{A descoberta da guitarrada}

Inicialmente, faz-se a seguinte pergunta: como uma segmentação praticamente proscrita, de um gênero musical também proscrito, do ponto de vista das iconografias hegemônicas, veio a emergir no cerne das narrativas em torno do que corresponderia a musicalidade paraense? Conforme ocorreu (e ocorre) com a chamada guitarrada. 
Grosso modo, a guitarrada surgiu em meados dos anos 1980, quando Carlos Santos, mais especificamente, Carlos Marajó (vulgo artístico), lançou por meio de sua gravadora, a Gravasom, uma série de coletâneas que incluíam lambadas, bregas e boleros cuja execução caracterizava-se pela onipresença melódica da guitarra elétrica.

(...) Bom, isso aí veio depois das Lambadas Internacionais, pelo som da guitarra que eles lá no caribe tocavam, os nossos músicos começaram a tirar o ritmo do som da guitarra, e eu lancei as guitarradas, que foi produzido pelo meu irmão Ari Santos... teve o Mestre Barata na guitarra, já falecido, que era o guitarrista... e fez muito sucesso. Lançamos uma série de discos de guitarrada. Na época outros artistas também fizeram o solo de guitarra, como o Vieira... teve o Aldo Sena, teve Curica, Mestre Curica, né... enfim... surgiram vários. $\mathrm{O}$ primeiro disco que eu fiz eu coloquei o pseudônimo de Carlos Marajó, quem gravou foi o Barata, com o pseudônimo de Carlos Marajó... foi apenas um nome que eu criei pra... eu sou do Marajó e tudo, mas o músico foi o Mestre Barata. (Carlos Santos. Entrevista realizada em 05/04/2012).

Sabe-se que, embora concebida como um adjetivo referente ao pulso musical è à predisposição dançante característicos dos ritmos caribenhos divulgados na região, a expressão lambada já aparecia como termo relativamente comum no linguajar festivo das gafieiras e bailes da cidade e proximidades durante a década de 1970. ${ }^{2}$ Em 1978 veio a estampar a capa do primeiro LP que associaria esta expressão a determinados contornos relativamente formais, o Lambadas das Quebradas, de Vieira e sen Conjunto. Guitarrista da cidade de Barcarena, Vieira incluiu em seu trabalho pioneiro composições próprias, instrumentais (com a guitarra assumindo toda a melodia). Estas canções incluíam elementos diversos - cúmbia, choro, carimbó, merengue, forró, bolero.

Após o lançamento do Lambada das Quebradas a versão de Vieira para o ritmo, que ainda naquele período constituía menos um gênero do que um adjetivo, adquiriu relativa projeção regional, majoritariamente entre as camadas populares da capital e do interior, que compunham os frequentadores dos bailes populares da época. Logo, muitos outros guitarristas surgiram neste ínterim, influenciados pelas composições de Vieira. Destacam-se os músicos Aldo Sena, Barata, Oseas e Solano. Em entrevista para esta pesquisa, Aldo Sena destaca o pioneirismo de Vieira:

(...) A lambada primeiramente foi Vieira... eu tenho que admitir que o Vieira foi o primeiro a gravar no primeiro ano e no segundo ano foi nós dos Populares de Igarapé Miri. Ele gravou Lambadas das 
Quebradas, nessa época em dois canais, que foi um grande sucesso... então eu tive um pouco de inspiração baseado no solo dele. (Aldo Sena. Entrevista realizada em 14/02/2012)

Atentando para as possibilidades mercadológicas, Carlos Santos resolveu investir neste segmento, lançando, com o pseudônimo de Carlos Marajó, vários LP's dedicados a canções populares executadas por solos de guitarras elétricas. Interessante: Carlos Santos (ou Carlos Marajó) não possuía maiores conhecimentos quanto à execução de qualquer instrumento musical. Embora estivessem registradas sob sua autoria, as canções incluídas nos LP's foram compostas por músicos que já faziam parte do cast de sua gravadora, como é o caso do guitarrista Barata; mas foi o então proprietário da Gravasom quem cunhou o termo guitarrada, ao utilizá-lo como referência nas estampas de seus lançamentos.

Ainda que a música divulgada pelos guitarristas identificados com este momento tenha adquirido relativo êxito, principalmente entre as camadas populares da região, o termo guitarrada se limitou à referência denominativa dos LP's lançados por Carlos Santos, não sendo usual como definição de algum gênero ou vertente específicas. De certo modo, o que hoje se entende por guitarrada, até então era compreendido, conforme dito antes, como uma versão, um estilo de execução da lambada e de outros gêneros contemporâneos populares regionalmente, nos anos 1980.

Com o arrefecimento do mercado destinado à lambada, vários artistas se afastaram de suas carreiras, como foi o caso dos guitarristas Vieira, Aldo Sena e Solano. Durante a década de 1990 suas composições foram praticamente proscritas das rádios comerciais, passando a representar, principalmente para as gerações mais juvenis, certo tipo de produção já ultrapassada, embora tenha se mantido em rádios e bailes populares.

Apesar da relativa proscrição, as lambadas de Vieira e de seus contemporâneos não deixaram de influenciar os empreendimentos de instrumentistas e produtores das gerações procedentes, dentre os quais se destacam os guitarristas Pio Lobato e Chimbinha. ${ }^{4}$ Em 1997, Chimbinha dedicou seu primeiro lançamento solo, o sugestivo Guitarras que Cantam, a canções instrumentais de brega, merengue e cúmbia, notadamente inspiradas nas produções de Vieira.

Outro guitarrista que ainda nos anos 1990 começou a se envolver com as 
potencialidades da lambada executada com a guitarra foi Pio Lobato. Diferentemente de Chimbinha, a formação musical de Pio Lobato remete à sua atuação em bandas de rock desde os anos 1980. Conforme relatou em entrevista para esta pesquisa, sua aproximação com a lambada se deu, mais efetivamente, em meados da década posterior, quando o guitarrista passou a integrar a banda Cravo Carbono e a realizar, concomitantemente, pesquisas com o ritmo. ${ }^{5}$

Inicialmente, seus empreendimentos praticamente se pautavam na apreensão de recursos para suas experimentações, conforme faziam muitos outros artistas contemporâneos; teria sido a partir de 2003, por conta da visita de pesquisadores escoceses à capital paraense, que o guitarrista então se viu enredado em um projeto de estandardiæação e iconização da guitarrada como expressão identitária paraense.

Em uma das apresentações da banda Cravo Carbono fora do estado, Pio Lobato conheceu Dj Dolores, artista sergipano/pernambucano que também realizava inúmeras incursões à música brasileira popular em seus projetos com a eletrônica. Assim, foi DJ Dolores que em 2003 contatou Pio Lobato the informando que havia um grupo de pesquisadores escoceses desenvolvendo um documentário e que teria indicado o guitarrista como cicerone em Belém.

Ao saber da visita, Pio Lobato logo procurou por informações acerca dos músicos contemporâneos de Vieira. O primeiro a ser encontrado foi Curica, banjista e fundador do conjunto de carimbó Uirapuru. No período em questão, Curica costumava se apresentar em um bar no bairro do Jurunas, e foi em um desses momentos que Pio Lobato teria lhe convidado a participar do documentário.

Convite aceito, Pio Lobato, acompanhado por DJ Dolores e pela equipe do documentário, seguiu até a residência do banjista. Curica lembra (em entrevista cedida à pesquisa em 14/03/2010) que nesta ocasião DJ Dolores teria lhe perguntado se não conhecia outro solista de guitarra que também pudesse participar, foi quando, por telefone, entrou em contato com o guitarrista Aldo Sena, que residia em um bairro vizinho. Ainda segundo Curica, havia muitos anos que Aldo Sena não tocava e nem gravava, tanto que o mesmo apareceu no local das filmagens sem instrumento, tendo que utilizar uma guitarra cedida pelo banjista. Aldo Sena e Curica apresentaram algumas de suas canções, devidamente registradas pelos documentaristas. De lá, Pio Lobato 
levou a equipe até o município de Barcarena, onde reside Vieira, para prosseguirem com os registros.

Pouco tempo depois, Pio Lobato contatou Curica para lhe propor a formação de um conjunto em parceria com Vieira e Aldo Sena. Logo, os três músicos que nunca haviam tocado juntos começaram a ensaiar para se apresentarem em um evento local denominado Seresta do Carmo. ${ }^{7}$ A partir de então, desencadeou-se uma série de acontecimentos que se desdobrou, como já dito, em um marcado processo de estandardização e iconização da música trazida pelos três artistas. Primeiramente, Pio Lobato precisava de um nome para o novo projeto. A ideia: Os Mestres da Guitarrada. Inspirada nos discos produzidos por Carlos Santos nos anos 1980. O lançamento: a Serestado Carmo.

A apresentação do Mestres da Guitarrada na Seresta do Carmo foi bastante exitosa, tanto que de lá o grupo recebeu inúmeros convites para participar de outros eventos nacionais e internacionais, conforme ressalta o, agora, Mestre Curica:

(...) Sim, desse show que nós fizemos na Seresta do Carmo, a gente peguemo um convite pra tocar no primeiro festival Rec Beat, em Recife. Metemos quinze mil pessoas... na antiga Recife, né. De lá, outro convite no outro ano, pra tocar no quinto Mercado Cultural da Bahia, no Pelourinho. Lá vai mais de trinta mil pessoas. Depois nós recebemos convite pra tocar no Itaú Cultural. Casa cheia! Aí fizemos cinco shows no Rio Cenário, no bairro da Lapa. Quando nós voltamos em 2004, recebemos outro convite pra fazer a revista Caras, na Ilha de Caras. Aí pá, pá, pá... Tocamos na Feira Cultural em Brasília, depois nós tocamos na Praça da Liberdade em Minas Gerais. Aí depois: "olha, nós tamos na disputa! Pra ir pra Alemanha...”. Eu nem sabia. Sabia que nós tava num rolo lá, né... Eram mil e quatrocentas bandas. Nós tiramos em primeiro lugar pra representar o Brasil na Copa do Mundo. O voto do Hermano Vianna... Eu tenho tudo as fotos aí. Aí rapaz, todas aquelas... como é que chama... aThalma de Freitas, Juliana Didone, aquele... Daniel Delsato, tudo lá metido. Quando terminou o Rio Cenário fui escutar só o sambão. Me metia lá. Toma cervejada!. A gente bebia pra encher o saco lá. A gente junto com vários artistas. Aí chegou um moreno, pediu pra sentar. Aí disse: "olha meu amigo..." Aí eu disse: "nós somos os Mestres da Guitarrada”. "Ah! eu já vi da televisão!”. (Curica. Entrevista realizada em 14/03/2010)

Segundo Pio Lobato, nos primeiros momentos do Mestres da Guitarrada, quando da procura por gravadoras interessadas, houve certa resistência dos veículos de comunicação locais. A alternativa mais pertinente seria a Fundação Paraense de 
Radiodifusão (FUNTELPA), haja vista seu precedente envolvimento com a divulgação de artistas paraenses. Ainda assim, o guitarrista comenta que só conseguiu convencer o seu então presidente, o Jornalista Ney Messias, a investir no grupo, após apresentar a gravação que produziu ao vivo junto com DJ Dolores, durante o festival Rec Beat, em Recife.

Com o aval de Ney Messias, o Mestres da Guitarrada se tornou também um projeto da FUNTELPA, transformando-se, inclusive, numa insígnia da gestão que teve início ainda no ano de 2003, com a assunção do citado jornalista ao cargo de presidente. O projeto, de modo geral, consistiu na gravação de canções inéditas de Vieira, Aldo Sena e Curica para a produção de um CD dedicado ao grupo. No entanto, tal produção não se limitou apenas à gravação das canções, pois o lançamento veio acompanhado de diversas estratégias publicitárias que envolveram a utilização de representações bastante marcadas. A própria embalagem do CD Mestres da Guitarrada já trouxe consigo várias referências iconográficas regionais, desde a sua confecção artesanal em miriti (ramo de uma palmeira utilizada para a feitura de brinquedos associados à festa do Círio de Nazaré), até a sua estampa, com menções aos bailes populares caracterizados pela presença de grandes estruturas sonoras e visuais denominadas aparelhagens. ${ }^{8}$

A divulgação do projeto não se furtou em fazer uso dos mais emblemáticos recursos comumente remetidos à região. Referências ao exotismo, à ingenuidade e à originalidade, dentre outras aposições correlatas (segundo uma típica concepção colonial), permearam e orientaram a emersão do grupo e de seu novo/velho gênero musical: a guitarrada.

O processo que tornou a guitarrada gênero musical não era inédito para os músicos e produtores paraenses. Desde pelo menos as décadas de 1960/70, haja vista, principalmente, o incremento fonográfico e a expansão da radiofonia e da televisão, a categorização de tradições musicais sob a forma de gêneros classificáveis nas estantes das lojas de discos se tornou basilar para a sensibilidade e a percepção. ${ }^{9}$ Neste sentido, os contornos, os limites e as fronteiras dos ritmos passaram a orientar os mais diferentes projetos.

Com o avanço e o estabelecimento de uma tônica industrial para o processo criativo artístico-musical ocorreu, regionalmente, o surgimento de um jogo performático 
que distintamente passou a envolver, com maior ou menor ênfase: mercado, gênero musical, território e identidade. ${ }^{10}$ Quando da estandardização e iconização da guitarrada, este jogo performático emergiu com toda a sua eficácia, mas agora com o acréscimo de se constituir parte de uma política de governo. Daí a dificuldade em se delimitar onde terminam as estratégias mercadológicas e onde começam os desdobramentos políticos identitários.

De todo modo, a empresa narrativa envolvida obteve ressonância entre vários músicos, que passaram a recorrer à guitarrada como referência para seus projetos. Todos tinham algo a dizer acerca de sua contribuição. Não somente: diversos elementos formais associados ao ritmo se tornaram cativos nos arranjos das composições de vários artistas contemporâneos, com destaque para as bandas La Pupuña e Cravo Carbono, e os músicos Felipe Cordeiro, Lia Sophia e, é claro, Pio Lobato. O êxito decorreu ainda no reaparecimento de outros guitarristas também tidos como precursores - Solano, João Gonçalves. Artistas nacionalmente conhecidos, como Caetano Veloso e Arnaldo Antunes e a banda de rock Titãs, também flertaram com o ritmo.

Ampliando as considerações, observa-se que tal visibilidade acontece em meio à sedimentação de uma narrativa em torno da formação identitária paraense, esta supostamente refletida em sua musicalidade e contemporaneamente representada não apenas pela guitarrada, mas também por outros gêneros, principalmente o tecnobrega. Entretanto, diferentemente deste último, a guitarrada traz especialmente consigo as menções à presença e à influência caribenha. O ritmo, nos discursos e representações, singulariza e situa a região em um domínio fronteiriço e periférico (do ponto de vista simbólico e geográfico). ${ }^{11}$ Neste ínterim, passou-se então a divulgar que, por se desenvolver em um contexto distante dos centros narrativos hegemônicos, a região teria se permitido uma maior volatilidade quanto às suas experiências, inclusive transnacionais, o que lhe forneceria uma centralidade às avessas. Mais ainda: a guitarrada corresponderia à expressão material, devidamente celebrada e performatizada em inúmeros registros. ${ }^{12}$

As experimentações presentes nos trabalhos de grande parte dos artistas identificados com este momento refletem justamente esta busca pela ideia de uma sensibilidade associada ao domínio fronteiriço e periférico, daí a suposta e marcada valorização do brega e de sua segmentação, o tecnobrega, que, junto com as guitarradas, 
passam a compreender a matéria-prima das articulações e projetos, orientando a formação do que alguns chamarão de cena: a Nova Música Paraense. Esta devidamente ritualizada e dramatizada por meio de vários recursos, dentre os quais, o festival Terruá Pará. ${ }^{13}$ O evento sem dúvida representou um marco para o processo de sedimentação desta respectiva cena, mas, se o brega e o tecnobrega também surgem aqui, torna-se pertinente e necessário circunstanciar o percurso pelo qual vieram a somar.

\section{A descoberta do tecnobrega}

Há uma ironia bastante marcada em torno do brega, situada não apenas na atenção que hoje se tem dedicado ao ritmo, em contraposição à sua precedente e relativa proscrição midiática nos anos 1990, mas no reconhecimento de que o brega, ao menos retoricamente, de modo algum se transformou em um produto do mainstream. Nem poderia, já que isto contradiria a sua absorção por parte deste mesmo mainstream. Noutras palavras, é justamente por se constituir como expressão dramaticamente periférica que o brega adquire importância central para as narrativas hegemonicamente construídas.

Por isso Hermano Vianna, antropólogo conhecido por sua navegabilidade e influência nos mais diversos mercados culturais brasileiros, quando esteve em Belém, em 2003, embora reconhecesse e valorizasse o estrondoso sucesso experimentado à época pela banda Calypso, não estava atrás de outras semelhantes, ainda que não negasse o potencial mercadológico do ritmo. Segundo observa, em fins dos anos 1990, ao aportar na cidade por conta do projeto Música do Brasil, Belém já havia se tornado a capital do brega, com vários artistas e centenas de CDs lançados anualmente para o consumo, sobretudo, das regiões Norte e Nordeste. Segundo o antropólogo, os músicos locais já nem chamavam o que faziam de brega, mas algo mais "sofisticado", o calypso paraense, produzido com "maior cuidado", guitarras dobradas (sobrepostas) e ritmo acelerado.

No entanto, este novo brega não constituía seu interesse maior. O próprio antropólogo comenta que se sentiu consternado ao tomar conhecimento de que Chimbinha havia deixado de atuar como músico de estúdio para se dedicar inteiramente à Banda Calypso. "Fiquei com pena: achava que bandas como a Calypso havia muitas, que o que faltava mesmo no brega era um instrumentista criativo como Chimbinha, capaz de dar uma sacudida boa nas fronteiras mais conformistas do gênero". 
(VIANNA, 2007)

Hermano Vianna, como um típico agente metropolitano (se se considerar o caráter colonial envolvido), estava em busca de algo realmente novo, e foi justamente em 2003, pelo Brasil Total, programa televisivo veiculado pela Rede Globo, que ele, supostamente, encontrou o que tanto almejava. ${ }^{14}$

O Brasil Total foi uma sequência intermitente de outros empreendimentos semelhantes (Programa Legal, Na Geral, Brasil Legal), programas televisivos que Hermano Vianna, em parceria com o produtor Guel Arraes e a atriz e apresentadora Regina Casé, já vinha desenvolvendo desde a década de 1990 na Rede Globo. A ideia consistia em percorrer o Brasil a procura de expressões tidas como inusitadas, especialmente associadas às camadas populares. Daí a visita do antropólogo à capital paraense.

No período em que esteve em Belém, pelo Brasil Total, Hermano Vianna foi ciceroneado pelo jornalista Vladimir Cunha e por Pio Lobato, responsáveis por apresentá-lo ao ritmo que desde então passou a ser divulgado como o santo graal que tanto havia perseguido: o tecnobrega. Especificamente: a "cadeia produtiva do tecnobrega". Conforme referido em diversas declarações. ${ }^{15}$

O brega que ele conhecera em sua visita anterior já havia percorrido outros caminhos mais ou menos imprevistos. A popularização das tecnologias de produção e reprodução de mídias audiovisuais, somadas ao advento de novos recursos digitais e eletrônicos ocasionou transformações significativas na evolução do ritmo.

Primeiramente, possibilitou o surgimento de vários pequenos estúdios bem mais acessíveis do que as gravadoras profissionais existentes. Por meio destes, artistas amadores passaram a produzir suas canções se utilizando dos expedientes oferecidos. A maioria era versões em português da música pop internacional em voga, destinadas às festas de aparelhagem e ao comércio informal de CD's e DVD's. Uma vez que a radiofonia e a indústria fonográfica local não absorveram este novo contingente, as festas de aparelhagem adquiriram importância central para sua divulgação. Mais do que isso: o brega produzido neste contexto, repleto de referências ao pop e à música eletrônica, tornou-se orgânico, como fruto das experiências éticas e estéticas ali encerradas. 
A origem do tecnobrega é incerta, em geral se atribui conjuntamente aos cantores Jurandir e Tonny Brasil, que no início dos anos 2000 resolveram acelerar ainda mais o ritmo e acrescentar riffs de guitarra, efeitos digitalizados, sintetizadores e algumas letras mais ou menos jocosas, hedônicas, cujos temas, sobretudo, evocavam o próprio universo das festas de aparelhagem.

A relativa facilidade com a qual poderia ser produzida, dispensando a necessidade de arranjos mais acurados (já que grande parte da produção era feita por meio de programas de computador), possibilitou a constituição de todo um filão informal devidamente amparado pelo incremento das festas de aparelhagem.

Quando da sua visita a Belém, em 2003, Hermano Vianna, acompanhado por seus anfitriões e especialmente interessado pelo novo ritmo, visitou estúdios, conheceu artistas e produtores, frequentou festas de aparelhagem e circulou pelos camelódromos da cidade. Ao verificar a maneira insólita com a qual o tecnobrega se propagava entre as camadas populares da capital paraense, o antropólogo e então produtor do Brasil Total teria reconhecido ali a expressão empírica das performances e articulações que compunham sua cruæada em busca das expressões artísticas reconhecidas por ele mesmo como genuinamente periféricas. Tudo se encaixava como uma "rede econômica e sociocultural" na qual seus elementos constituintes atuariam para sua manutenção.

Pouco tempo depois de seu encontro com o tecnobrega, Hermano Vianna publicou no jornal Folha de São Paulo um artigo em que apresenta o novo ritmo como a consolidação de “(...) uma nova cadeia produtiva, amparada em bailes de periferia, produção de CDs piratas e divulgação feita por camelôs” (VIANNA, 2003). Em seu texto, o antropólogo, de forma apologética, não economizou nas representações em torno dos aspectos supostamente inusitados, espontâneos, autônomos, periféricos e até mesmo ingênuos desta mais recente expressão. $\mathrm{O}$ tecnobrega passou a representar algo de subversivo e pujante, frente ao desgaste da indústria cultural, tida como conservadora e elitista.

A repercussão adquirida pelo artigo de Hermano Vianna refletiu na reprodução de um conjunto de lugares comuns presentes e recorrentes nas muitas declarações posteriores sobre o tecnobrega e sua cadeia produtiva. Todos (e aqui me refiro a vários 
jornalistas, produtores e artistas) resolveram se juntar ao antropólogo na defesa da suposta criatividade revolucionária das periferias brasileiras.

O mais interessante é que, excetuando a grande curiosidade que as festas de aparelhagem também despertaram entre estes novos entusiastas, as atenções se voltaram majoritariamente para a cantora Gaby Amarantos, que Hermano Vianna conhecera durante as gravações do programa Brasil Total. Gaby Amarantos, que na época fazia parte da banda Tecnoshow (junto com DJ Iran), talvez pela sua participação no referido programa, tornou-se o elo exclusivo entre a mídia nacional e o tecnobrega. No entanto, apesar de algumas poucas participações em programas televisivos populares, sua projeção não se deu, ao menos inicialmente, entre as camadas populares dos grandes centros urbanos, mas no âmbito do chamado circuito alternativo.

Isto pode parecer um paradoxo, mas não é nada eventual, pois indica o recente surgimento de nichos mercadológicos e discursivos que passaram a adotar, sob a égide do exotismo, uma espécie de combinação que toma o estravagante manifestação autêntica da contemporaneidade. Digo extravagante porque assim precisa ser estética e eticamente concebida para que seja então redimida. Tal deslocamento soaria como uma idiossincrasia pós-moderna, mas se percebe que é mais um arranjo semelhante a outros tantos precedentes. ${ }^{16}$

Por isso, não se pode afirmar que a ascensão do tecnobrega, na prática, tenha decorrido de um avant garde (embora, discursivamente tenha sido). Antes mesmo do alarde produzido em torno deste novo ritmo, a música romântica popular, que no Brasil, de modo pejorativo, convencionou-se adjetivar de brega, já estava também sendo redimida pelo nicho mercadológico e discursivo que passou a atribuir certa autenticidade às expressões reconhecidas como extravagantes ou cafonas. Haja vista a variedade e a quantidade de matéria-prima regional, este fenômeno se refletiu de modo notável em Belém. Muitos artistas identificados com a música paraense contemporânea passaram a investir em regravações de bregas populares da década de 1980, mas agora com arranjos tidos como mais sofisticados, repletos de referências ao jazz, à bossa nova, à $M P B$ e à salsa. Isto se tornou notório nos anos subsequentes à projeção do tecnobrega e da guitarrada.

Certamente, as notícias sobre os predicados do tecnobrega logo chegaram aos 
ouvidos de segmentos das camadas médias da capital paraense, e não tardou para que Gaby Amarantos e sua música despontassem nas festas e nos festivais do circuito alternativo local. A transformação de Gaby Amarantos, com sua tão enfatizada extravagância, em artista cult, consoante muitos passaram a identificá-la, foi devidamente celebrada em vários registros como uma subversão das inibições que caracterizariam o gosto das classes médias brasileiras.

Entretanto, apesar de já experimentar uma relativa visibilidade, a habilitação do tecnobrega, mais especificamente, de Gaby Amarantos, do ponto de vista hegemônico, somente foi evidenciada com a realização do primeiro Terruá Pará, ocorrido em São Paulo no ano de 2005.

Durante o festival, em meio às tradicionais e legitimadas referências, Gaby Amarantos subiu ao palco acompanhada por Dj Iran e Pio Lobato. Embora sua participação tenha se limitado à apresentação de algumas das experimentações que a cantora, o dje o guitarrista vinham desenvolvendo, a presença, mesmo que de soslaio, do tecnobrega, gênero musical popular recém criado e descoberto, assinalava que algo estava acontecendo. Em sua apresentação Gaby Amarantos não se furtou em fazer aposições à condição periférica do tecnobrega. Algo que, inclusive, tornou-se comum em suas inúmeras performances.

Assim, o tecnobrega, por meio de sua principal representante adquiriu no decorrer da segunda metade dos anos 2000, maior visibilidade (ainda que relativamente restrita), mas foi em 2010, após a apresentação de Gaby Amarantos no festival Recbeat, em Recife, que o tecnobrega teria experimentado uma súbita expansão. Segundo a cantora paraense, em entrevista para a Revista Trip (2011), sua apresentação no festival provocou bastante euforia no público, chamando a atenção de produtores presentes. ${ }^{17}$

Pouco tempo depois já estava se apresentando em vários programas televisivos, estampando capas de revistas e concedendo entrevistas para jornais e sites da internet. Muitos artistas conhecidos nacionalmente passaram a se interessar não só pela música, mas também pela imagem da cantora. A então Rainha do Tecnobrega, como ficou conhecida, obteve (e obtém) grande exposição midiática, ganhando diversos prêmios, inclusive internacionais, e realizando shows por todo o Brasil. 
Entretanto, o tecnobrega de Gaby Amarantos se tornou menos a música das periferias e baixadas da capital paraense do que uma espécie de formatação elaborada a partir de uma ideia acerca do que presumivelmente as camadas populares de Belém dançam ou escutam, sobretudo nas festas de aparelhagem. Tanto o tecnobrega quanto a música de Gaby Amarantos já são raros nestes registros, a música que domina os repertórios das aparelhagens é o melody (também chamado de eletromelody), que alguns diriam ser a versão local do tecnobrega.

Independente ou não da fidedignidade, com o filão aberto por Gaby Amarantos, o tecnobrega (juntamente com a guitarrada e o brega) tornou-se comum nas experimentações e incursões de muitos artistas contemporâneos brasileiros, principalmente, é claro, paraenses. Surgiram ainda outros grupos também identificados com o tecnobrega e, agora, mais notadamente, com o eletromelody. Alguns destes também passaram a experimentar uma relativa projeção para além da região.

Sedimentava-se a cena reconhecida por Nelson Motta quando esteve, em 2011, na plateia do Terruá Pará, evento que passou a condensar dramaticamente, do ponto de vista performático e narrativo, como um espelho, todas as tendências que iriam compor a então nova música paraense. Aqui cabe uma indagação que permite ampliar ainda mais as perspectivas sobre este processo: Em que consiste, afinal, o Terruá Pará?

\section{O Terruá Pará e a identidade encenada}

Apesar de há muito já se observar, como uma recorrência, aquele mesmo jogo performático em torno das relações entre gênero, mercado, identidade e território, verifica-se que tal perseverança, consoante o que se entenderia por música paraense, até então se deu por decorrência de um entrecruzar de empreendimentos relativamente fragmentados, ainda que orientados pelos mesmos pressupostos. Não constituía necessariamente uma condensação deliberada, mais ou menos pontual e dramatizada do que viria a ser esta respectiva música paraense. No entanto, é a partir dos anos 2000 que o mencionado jogo performático se institucionaliza como uma empresa específica e devidamente ritualizada. Neste ínterim, surge o Terruá Pará, projeto desenvolvido pela Fundação de Telecomunicações do Pará, a FUNTELPA, na gestão do jornalista Ney Messias. 
O primeiro Terruá Pará ocorreu em 2005 na cidade de São Paulo, mas sua consolidação constituiu um desdobramento dos vários eventos que já aconteciam na capital paraense, principalmente os festivais Cultura de Verão e Cultura de Música e o Prêmio Cultura de Música, promovidos após a assunção do jornalista Ney Messias à direção da FUNTELPA, em 2003. Desde o início de sua gestão Ney Messias já tornava público que a sua atuação se comprometeria, sobretudo, com a promoção do que o próprio convencionou denominar de Música Popular Brasileira (MPB) feita no Pará. Isto pressupunha a divulgação e a fomentação do trabalho de artistas por meio da realização de espetáculos e da veiculação radiofônica e televisiva.

Embora se observe que subsequentemente houve um relativo alargamento quanto à noção do que corresponderia esta MPB paraense, ao menos inicialmente a atuação da FUNTELPA, se comparada a momentos posteriores, ainda era bastante restrita e exclusiva. Não que a sua gestão tenha se caracterizado por uma gradual subversão das concepções discursivas vigentes, mas, certamente, houve reajustes, negociações e deslocamentos que ampliaram tais concepções, na medida em que passaram a compreender também vicissitudes e disposições contemporâneas, principalmente no que tange às performances acerca das relações entre as tradicõoes locais e a modernidade global. Por isso a impressão de que, com a chegada de Ney Messias, a FUNTELPA (principalmente se se levar em conta as gestões precedentes) assumiu um matiz mais pop, com a realização de eventos majoritariamente direcionados ao público juvenil, e a visível preocupação com as convergências mercadológicas.

De todo modo, o que se percebe é que a gestão de Ney Messias, até certo ponto, menos inventou um novo olhar sobre a música paraense do que trouxe para o domínio estatal tendências que há algum tempo vinham se fortalecendo na região. Desde a virada deste último milênio, muitos artistas, em seus projetos com o rock, a eletrônica ou o pop, já incursionavam pela musicalidade tradicional. Vários destes artistas adquiriram certa visibilidade regional, haja vista o advento de espaços e eventos dedicados às suas apresentações, grande parte promovidos por particulares ou pelo governo municipal.

Daí o matiz característico de todas as edições do Festival Cultura de Verão. Ocorridos anualmente no decorrer do mês de julho (o mês das férias escolares), durante toda gestão de Ney Messias, o festival abrangeu desde os artistas já legitimados e reconhecidos (Nilson Chaves, Lucinha Bastos, Almirzinho Gabriel, Trio Manari, Lia 
Sophia, Pedrinho Callado, Iva Rothe, Alcir Guimarães), até bandas de rock: tanto as mais atentas à matéria-prima da região (Coletivo Rádio-Cipó, Cravo Carbono, La Pupuña), quanto as mais exclusivamente dedicadas ao gênero (Madame Saatan, Norman Bates, Suzana Flag, A Euterpia), além de bandas de reggae e conjuntos de carimbó.

A atenção de Ney Messias esteve voltada para as tendências em voga, principalmente entre o público mais jovem das camadas médias. Isto ficou mais evidente quando o então diretor da FUNTELPA resolveu, em 2004, promover uma edição do Festival Cultura de Verão na ilha de Algodoal. Situada no litoral nordeste do estado, Algodoal, atualmente, representa um dos principais destinos de certos segmentos juvenis das camadas médias da região. Diferente de outros locais de veraneio também frequentados por estes mesmos estratos sociais, Algodoal se tornou atrativa por, presumivelmente, trazer consigo uma ideia de rusticidade, associada à natureza, ao carimbó (bastante presente) e a certa nostalgia hippie.

A ousadia foi bastante exitosa. De acordo com dados informais divulgados pela FUNTELPA, o público chegou a aproximadamente 30.000 pessoas e o festival se transformou num marco das ações empreendidas por Ney Messias, que logo se ocupou com o planejamento de uma segunda edição para 2005, mas, agora, outras ideias lhe vieram.

A guitarrada, o tecnobrega e seus representantes já haviam adquirido certa popularidade, inclusive entre os novos artistas que despontavam. Bandas, compositores e intérpretes contemporâneos, atentos também às influências estilísticas em voga no Brasil e no mundo, aproximavam-se cada vez mais da musicalidade tradicional da região, concomitante a aceitabilidade do público.

Portanto, foi diante desta movimentação que Ney Messias teve a ideia de criar um projeto que sistematizasse e divulgasse como uma cena para todo o Brasil, o potencial mercadológico e discursivo do que seu próprio idealizador passou a chamar de nova música paraense. O intuito, grosso modo, era produzir um festival contendo uma espécie de seleção especial de artistas e ritmos reconhecidos como mais promissores do ponto de vista dos interesses e demandas da indústria musical brasileira.

Segundo Pio Lobato, que participou de todo este planejamento, logo de início 
Ney Messias percebeu a necessidade de que o projeto trouxesse uma grife, ou seja, que estivesse vinculado ao nome de algum produtor renomado; foi então que entrou em contato com Carlos Eduardo Miranda e Cynthia Zamorano, cujos currículos incluem a produção de vários artistas nacionalmente conhecidos. O plano era trazê-los para a edição 2005 do Festival Cultura de Música que ocorreria em Algodoal, quando poderiam avaliar as reais possibilidades dos artistas paraenses. A escolha pelos citados produtores não foi aleatória, pois ambos possuem seus nomes associados à manguebeat, que na década de 1990 lançou nacionalmente vários artistas e bandas da capital pernambucana.

Quando da realização do festival em Algodoal os dois produtores, presentes durante todo o evento, fizeram as suas primeiras ressalvas. As bandas mais exclusivamente identificadas com o rock ou com o reggae foram logo descartadas. As atrações que mais chamaram a atenção de Carlos Eduardo Miranda e Cynthia Zamorano, conforme declarações que ambos deram ao conhecido site de música Senhor F., foram o Mestres da Guitarrada e o Metaleiras do Pará, além das bandas La Pupuña (com a participação de Gaby Amarantos), Coletivo Rádio Cipó (com participação de Dona Onete e Mestre Laurentino) e Cravo Carbono. Sendo assim, devidamente avalizado, o projeto de Ney Messias se delineava cada vez mais.

Neste momento, de tantas celebrações à musicalidade paraense - supostamente diversa, livre, criativa e autêntica-, a metrópole surge com todo seu encargo de representações como a meta a ser atingida. Mais ainda: a metrópole orientaria a colônia na maneira com a qual deveria ser atingida. ${ }^{18}$

Isto, de modo geral, não causa tanta surpresa, seriam apenas estratégias mercadológicas quaisquer em torno de um nicho a ser conquistado, não fosse por um detalhe: constituiu uma política estatal e que, por isso, obteve notadamente desdobramentos para o domínio da identidade. Apresentar o potencial da Nova Música Paraense, com todos seus atributos, para a metrópole, por meio de ações e ritualizações, é mais do que um jogo publicitário, pois, como um espelho, envolve uma série de representações auto-direcionadas.

As noções acerca da singularidade e do caráter genuino estarão no cerne conceitual da materialização do projeto de Ney Messias, o Terruá Pará, uma institucionalização, sob a tutela de Carlos Eduardo Miranda e Cynthia Zamorano, do que corresponderia a 
riqueza musical paraense. Um festival que abrangesse todas as tendências, principais artistas e ritmos, formatado especialmente para os grandes eixos mercadológicos do país.

De acordo com Ney Messias, a respectiva denominação se deu pela alusão ao caráter exclusivo da música paraense: “(...) considerada como única e cuja especialidade é comparada com o champagne produzido na região francesa homônima, daí o nome 'terroir', pois esta música só poderia ser produzida na terra paraense e sua riqueza está diretamente e intrinsecamente ligada ao local que lhe deu origem” (MESSIAS, 2012).

Sendo assim, foi com esta premissa que em 2006 ocorreu, no Teatro Ibirapuera, em São Paulo, o primeiro Terruá Pará. O lançamento do festival aconteceu em meio a uma ampla divulgação. A ênfase midiática envolveu, sobretudo, a diversidade de artistas e ritmos, conforme noticiado pelo jornal Estadão, versão eletrônica do impresso $\mathrm{O}$ Estado de São Paulo:

\footnotetext{
A música paraense vai muito além da Banda Calypso. E isso é o que poderá ser conferido amanhã, sábado e domingo, no Auditório Ibirapuera. Mais de 60 artistas, vindos de diversas regiões do Pará, vão se apresentar no espetáculo Terruá Pará, mostrando de batidas eletrônicas misturadas ao tecno do Pará ao toque de raiz do carimbó, passando pela guitarrada consagrada pelos mestres Curica, Vieira e Aldo Sena. (ESTADÂO, 2006)
}

O festival corresponderia a uma sintetização das múltiplas e entrecruzadas disposições que compõem o domínio da música paraense, mas, embora se observe uma relativa diversidade de atrações, as atenções estiveram majoritariamente voltadas para o tecnobrega e para a guitarrada.

A maioria das menções buscou sublinhar as imagens e representações já recorrentes, principalmente no que se refere à suposta volatilidade com a qual a música se renova por meio das convergências contemporâneas. Portanto, a diversidade é tomada como carro-chefe, esta devidamente orientada pelas, supostamente, diferentes combinações entre as tradições locais e a modernidade global.

Cenograficamente o festival desde já evidenciava certo apelo identitário. O emprego do miriti e as referências às aparelhagens indicavam o que se queria enfatizar.

Durante o evento os artistas se revezaram, apresentando-se ora somente com a 
banda de apoio, ora em parceria ou com o acréscimo de mais instrumentistas. A mistura constituiu a tônica do festival, mas esta, notadamente associada à presença do tecnobrega (representado, sobretudo, por Gaby Amarantos e DJ Iran) e da guitarrada (com a apresentação do Mestres da Guitarrada, de Pio Lobato e da banda La Pupuña).

Se havia alguma preocupação com o êxito do festival, esta logo se dissipou. A repercussão foi imediata, inúmeros jornalistas, produtores e artistas (alguns inclusive presentes no evento) publicaram notas, artigos e colunas em impressos, sites da internet e demais veículos. Todos estavam atentos às possibilidades trazidas e oferecidas pela cena musical paraense. Em artigo para o site O Esquema, o jornalista Alexandre Matias anuncia que “(...) o evento vem consagrar a capital paraense como um novo polo de produção cultural no país” (MATIAS, 2006). Embora ressalve: "Mas por que só agora?”. Prosseguindo com seu texto, Alexandre Matias acrescenta que Belém surge na pauta cultural brasileira forte o suficiente para cobrar uma dívida para com a região Norte, mas sem conseguir se livrar da pecha de exotique: "Era como se a floresta tivesse mandado uma expedição de boas vindas à civilização, puros ritmos, danças e figurino espalhafatosos e um comportamento musical incendiário que acende a velha metáfora sobre a Amazônia - o inferno verde" (MATIAS, 2006).

De qualquer forma, o sucesso obtido pelo Terruá Pará veio evidenciar a gestão de Ney Messias que ainda durante o ano de 2006, inseriu na grade da Rádio e TV Cultura local (veiculada pela FUNTELPA), um programa semanal denominado Terruá Pará, encabeçado por ele e dedicado à apresentação ao vivo de artistas paraenses, semelhante a outros já incluídos na programação.

Entretanto, com a mudança da gestão governamental, em 2007, e a assunção da jornalista Regina Lima à presidente da FUNTELPA, cuja administração foi voltada majoritariamente para a atuação radiotransmissora e televisiva, houve um visível arrefecimento das ações relativas à divulgação da cena promovida por seu antecessor, principalmente no que compete à promoção de festivais e demais eventos. Contrariamente, não se observa neste mesmo período, o abrandamento da excitação midiática em torno da música paraense, assim como não houve uma diminuição de eventos promovidos na cidade por outros agentes. Artistas como Dona Onete, Pio Lobato e Gaby Amarantos, experimentavam, cada vez mais, projeção nacional, sobretudo no âmbito do chamado circuito alternativo. 
Outros, como Lia Sophia, Felipe Cordeiro, que por sinal nem participaram do primeiro Terruá Pará, também aproveitaram o filão aberto que, neste momento, já possuía contornos bem definidos quanto ao que se fazia de mais interessante para o mercado nacional.

O projeto de Ney Messias somente seria retomado cinco anos mais tarde, em 2011, com o retorno do governo ao qual se vinculara e seu consequente regresso ao domínio estatal, mas agora como gestor da Secretaria de Comunicação, órgão que abrange, dentre outros setores, a própria FUNTELPA. Na direção desta, assumiu a jornalista Adelaide Oliveira, relativamente afinada com a gestão de Ney Messias.

Como novo Secretário de Comunicação, o então idealizador do Terruá Parálogo retomou sua parceria com os produtores Carlos Eduardo Miranda e Cynthia Zamorano - eram outros tempos. A guitarrada e o tecnobrega (somados ao carimbó e ao brega), conjuntamente, já despontavam como matéria-prima básica e necessária a qualquer artista e projeto que almejasse alguma visibilidade. Daí que não se observava mais o enfoque no potencial de gêneros musicais específicos, mas as suas utilizações e aplicações nos empreendimentos musicais. A influência caribenha, por sua vez, praticamente se institucionalizou como uma narrativa que passou a subjazer tais empreendimentos, fornecendo-lhes um teor de coerência e, ao mesmo tempo, legitimidade e singularidade. Noutras palavras, consoante o discurso vigente, a música paraense possuía essa ou aquela feição característica porque somente no Pará transcorreram as contribuições fundamentais à sua conformação. Mais ainda: mesmo disponibilizadas, estas contribuições só foram possíveis graças ao caráter volátil do paraense, isento das inibições típicas dos grandes centros. ${ }^{19}$

A identificação com o Caribe emerge de modo pujante, bastante ressaltada por diversos artistas, jornalistas e produtores de todo o Brasil. Nada representaria tanto o suposto caráter genuíno e dinâmico da música paraense do que a observável influência de inúmeros gêneros caribenhos. Tal influência deveria ser não apenas mencionada, mas estandardizada. A Amazônia, o Pará e a região Norte se tornariam então o que fosse atraente para a metrópole.

Abalizados, discursivamente, pela condição periférica e fronteiriça que teria 
possibilitado não apenas a influência musical caribenha, mas o surgimento da guitarrada e do tecnobrega, vários artistas paraenses já circulavam pelos grandes centros do país quando Ney Messias, logo em 2011, promoveu mais uma edição do Terruá Pará.

Se em 2006 houve um clima de desafio, o novo Terruá Pará surge mais consolidado. O evento, ocorrido também no Teatro Ibirapuera, não constituiu exatamente a exposição das possíveis potencialidades, mas uma reunião do que já se havia demonstrado promissor, devidamente orbitado por alguns artistas e grupos já há muito legitimados regionalmente. Por isso a edição de 2011 contou com apenas 15 atrações (além da banda de apoio, que foi a mesma do festival anterior). ${ }^{20}$

O público paulista até certo ponto conhecia parte dos artistas que se apresentariam, assim como sabia mais ou menos o que esperar de suas performances. Inclusive porque o evento veio acompanhado por uma divulgação massiva em impressos e em veiculações televisivas e na Internet. ${ }^{21}$

A Revista Trip, de circulação nacional (por meio do jornalista Luís Felipe Tavares), anunciou o evento como a reunião do que havia de melhor na música popular paraense em 2011, referindo-se ao rolde artistas como um panteão, ressaltando também velhas imagens e representações em torno da maneira como o tradicional e o moderno eram performatizados: "Na versão 2011 do festival estarão presentes grandes figuras da música popular do norte do País, desde mestres do carimbó e ícones da guitarrada até astros do tecnobrega, mesclando o novo e o tradicional diante do público paulista” (TAVARES, 2011).

O festival seguiu as mesmas estrutura e dinâmica de seu antecessor, com a cenografia em miritis (incluindo uma armação que simulava as antigas aparelhagens) e com os artistas se revezando por meio de parcerias.

A repercussão do evento foi maior do que a do primeiro. No site ParáMúsica o jornalista Fábio Gomes comenta que, diferente de 2006, a edição de 2011 foi transmitida ao vivo pela TV Cultura (de Belém) e pela Record News (de São Paulo, em rede nacional aberta) e na Internet, com divulgação simultânea em várias redes sociais eletrônicas. De acordo com o jornalista, as publicações referentes foram bastante elogiosas. ${ }^{22}$

As resenhas dos dias seguintes foram amplamente favoráveis ao 
Terruá Pará, a começar pelo texto "O tremor do jambu é gostoso demais" publicada no dia 25 - "Viemos de nossa terra fazer barulho em terra alheia", terminou todo mundo junto, exalando profissão de fé que, tomara, se repita cada vez mais frequentemente daqui por diante". O site R7 publicou uma galeria de fotos do primeiro dia, além de uma resenha de Paola Correa. O site Shhh.fm, junto ao texto de Jackson Araújo "A Saia Imaginária" (referência ao pedido de Gaby Amarantos aos espectadores, para "segurar na mão a saia imaginária e sair por aí dançando o carimbó”), colocou um player com a gravação de oito músicas do show. Outros textos foram publicados no Blog do Espaço Aberto e no blog de Paulo André Nassar ("Singular. Essa talvez seja uma das poucas palavras capazes de dar conta do que foi o Terruá Pará. Uma mistura firme de música popular com erudita, violão amazônico com carimbó, e brega com guitarrada."); a postagem inclui um vídeo de "Igapó", com Sebastião Tapajós e Orquestra Juvenil de Violoncelos da Amazônia. O texto "Égua, mano! Terruá Pará surpreende com sua diversidade e energia contagiante", vem se mantendo como o mais lido do site Colherada Cultural, desde sua publicação no dia 27. Já o Diário do Pará do dia 28 trouxe a resenha de Timóteo Timpin Pinto, que destacou a perfomance de Dona Onete e também a da Gang do Eletro, à qual dedicou um texto à parte, ressaltando os elogios que o grupo recebeu do crítico e produtor Nelson Motta, que assistiu o show do dia 25. No dia 27, Nelson Motta enviou um e-mail ao cantor Marco André dizendo ter adorado o Terruá, em especial as apresentações de Felipe Cordeiro, Gaby Amarantos e Lia Sophia. Marco em seguida encaminhou a mensagem a Ney Messias; ambos não tardaram a dividir a boa nova com seus seguidores no Twitter (GOMES, 2011).

Da edição de 2011 vários outros empreendimentos se sucederam. ${ }^{23}$ Quando do plebiscito sobre a divisão do Estado do Pará, o projeto foi utilizado pela gestão governamental como um pretenso recurso de sensibilização identitária. Versões mais ou menos adaptadas do espetáculo foram realizadas em municípios estratégicos, de onde partiam as demandas pelo processo de emancipação. A ideia, supostamente, era fomentar, por meio do Terruá Pará, algum tipo de sentimento de pertença, em regiões nas quais as alegorias encenadas pelo espetáculo até então possuíam pouca ou nenhuma reverberação.

No ano seguinte ocorreu ainda o primeiro Terruá Pará na capital paraense. Realizado no Teatro da Paz, o evento contou com a participação de alguns dos artistas que estiveram nas edições anteriores e trouxe um declarado clima de celebração. O vislumbre em torno das possibilidades trazidas pela guitarrada, pelo tecnobrega e pelas remissões ao Caribe já poderia ser notadamente identificado em grande parte das performances apresentadas pelas várias atrações selecionadas. Isto evidenciou as 
nuances assumidas, deliberadamente, pelos idealizadores do espetáculo. Ao mesmo tempo, estas mesmas nuances evidenciaram também as muitas contradições envolvidas, ou seja, o marcado exclusivismo de um projeto que se propôs a representação da diversidade de artistas e estilos paraenses, ou, como apresentava Ney Messias em diversos registros: a busca pelo sotaque perdido.

\section{Considerações}

Como se observa, por meio de um jogo de espelhos, a música paraense é definida, sedimentada, curiosamente, não somente do ponto de vista estilístico, propriamente dito, mas também discursivo. Se as grandes narrativas são inerentemente não contingenciais, a volatilidade tão anunciada e celebrada é fixada e aprisionada retoricamente. O caráter subversivo, igualmente defendido, transforma-se numa representação rotineiramente aguardada por quem ou pelo que deveria ser subvertido. Agora, obrigatoriamente, tudo é possível, não sendo permitidas outras possibilidades.

A partir das narrativas em torno da evolução da música paraense procurei discutir como certos mitos, em sua presumível sincronicidade, permeiam e orientam as mais heterodoxas negociações, estratégias e deslocamentos diacronicamente norteados. Se, tal como apõe Frederik Barth (2011), a construção das identidades implica em processos de seleção de traços culturais a partir dos quais os atores elaboram seus critérios de consignação ou de identificação, é preciso dizer que estes mesmos processos de seleção não são arbitrária e aleatoriamente situacionais, pois trazem consigo, muitas vezes, como um fantasma, aquilo que Marshall Sahlins (2008) chama de a "inescapabilidade" do passado. No entanto, este passado não surge aqui apenas como uma herança perseverante, mas como uma estrutura que, neste caso, justapõe a condição periférica da região (fixada por meio de uma conformação tipicamente colonial). Neste ínterim, os entrelaçares sociológicos e simbólicos produzem um emaranhado de possibilidades narrativas. Na prática: o proscrito se torna recomendável (inclusive como proscrito), a volatilidade é formalizada, o marginal surge como balizar, a periferia se centraliza e o centro se periferiza. Embora, ratifico, nada disso pressuponha o acaso das condições circunstanciais. Tudo tem o seu devido lugar.

\section{Notas}


1. Nestas primeiras décadas dos anos 2000, o termo foi, publicamente, repetido e propagandeado por meio de diferentes veiculações e por vários jornalistas e produtores influentes nesse domínio, como Ney Messias e Eduardo Miranda.

2. Segundo Expedito Leal (2010), o termo lambada, originalmente significando a prática de ingerir uma dose de cachaça, teria sido utilizado pelo radialista Haroldo Caracciolo em seus programas radiofônicos durante a década de 1970 para se referir aos diferentes gêneros oriundos do Caribe: "Há quem diga, igualmente, que ele passou a usar o neologismo para substituir o ritmo merengue ouvido nas Antilhas e que foi modismo em Belém, especificamente no subúrbio, como referência musical tanto para ouvir como preferencialmente para dançar" (LEAL, 2010, p 105). Outros atribuem a autoria da lambada ao músico Pinduca, que em 1976 lançou em seu LP No Embalo do Carimbó e Sirimbó do Pinduca, Vol 05, uma canção instrumental intitulada Lambada Sambão. De qualquer forma, no ano em que esta canção foi gravada o termo já era comum nos ambientes festivos. Haroldo Caracciolo, talvez pelo alcance que o rádio possuía naquele período, é mais notoriamente reconhecido como autor da vinculação da lambada a certos pressupostos formais.

3. Aldo Sena, por exemplo, vendeu sua guitarra ainda no início dos anos 1990, dedicando-se desde então à venda e à manutenção de calçados, só retornando às atividades artísticas no início dos anos 2000 (informação obtida por meio de entrevista em 14/02/2012).

4. Em registro para o projeto Música do Brasil (pretenso mapeamento da diversidade musical brasileira, produzido por Hermano Vianna e veiculado em 1999 e 2000 pela emissora de televisão MTV), Chimbinha relata que teria se interessado pela guitarra ainda na infância, nos anos 1980, influenciado pelas lambadas de Vieira, Aldo Sena e outros. Adulto, o então guitarrista, que já havia adquirido certa notoriedade regional como produtor, compositor e arranjador junto a vários artistas de brega, não deixou de reproduzir certos elementos que, de maneira observável, remetem ao estilo que orientou sua formação.

5. Pio Lobato não foi o único a considerar as possibilidades que a música paraense popular poderia oferecer no âmbito das experimentações com o rock ou demais estilos urbano-contemporâneos. Vários outros artistas, muitos destes influenciados pelo manguebeat pernambucano, já desenvolviam, neste mesmo período, incursões semelhantes. As representações em torno das combinações entre o tradicional e o moderno, o global e o local, emergiam e recorriam como uma narrativa autêntica, hegemonicamente apropriada e reproduzida. A partir dos anos 2000, em Belém, houve um relativo incremento quanto à visibilidade de novos (e outros não tão novos) artistas. Contribuiu para isto o advento de festivais e demais eventos, somados aos diversos espaços, bares, boates e ambientes noturnos em geral, e às veiculações televisivas e radiofônicas de canções e artistas por meio da FUNTELPA (Fundação Paraense de Radiodifusão).

6. Em entrevista para a pesquisa (em 07/07/2013), Pio Lobato relata que em 1999 já assumia a influência de Vieira em seus projetos quando pôde, enfim, conhecê-lo pessoalmente. Segundo Hermano Vianna (2007), em texto publicado no site Overmundo, o encontro entre os dois guitarristas ocorreu durante as filmagens para o projeto Música do Brasil em Belém, quando a banda Cravo Carbono serviu de apoio para a apresentação de Vieira. A partir de então Pio Lobato teria mantido contato com Vieira, visitando-o diversas vezes em seu município domiciliar, Barcarena.

7. Evento patrocinado pelo governo municipal que ocorria mensalmente em uma das praças do Centro Histórico de Belém, e que atraía grande público, principalmente universitários, artistas e segmentos das camadas médias em geral.

8. Empreendimentos identificados pela utilização de suntuosos aparatos eletrônicos, sonoros e 
visuais; diferenciados pelo estilo de festas que propõem; pelo público que atraem e por suas dimensões e feições diversas. As aparelhagens foram responsáveis pela projeção das festas de aparelhagem, tal como ficaram notoriamente conhecidas e denominadas na capital paraense e demais municípios próximos nas últimas décadas. No início dos anos 2000, as festas de aparelhagem e outros demais elementos então tidos como populares e/ou periféricos (brega, lambada), tornavam-se cada vez mais estandardizados no âmbito das narrativas acerca da identidade paraense.

9. Certamente isto não se restringe à experiência paraense. Ainda na primeira metade do século XX, intelectuais como Theodor Adorno e Walter Benjamin já se preocupavam com estas mesmas questões em seus estudos em torno da arte e da música na contemporaneidade. Ver Adorno (1996) e Benjamin (2000).

10. Por jogo performático considero o caráter, as negociações e as estratégias com as quais estes quatro elementos foram articulados simbólica e socialmente por sujeitos e coletividades em momentos diferentes.

11. Como exemplo, cito trecho do relato do produtor gaúcho Carlos Eduardo Miranda (publicado no jornal paraense O Liberal), responsável pela produção do chamado Terruá Pará, espetáculo promovido pelo governo do estado (nos anos 2006 e 2011); que reúne vários artistas então inseridos em um mainstream musical regional. O Terruá Pará, notoriamente, corresponde a um dos mais importantes empreendimentos de divulgação mercadológica e identitária da produção musical paraense consoante um forte discurso remissivo às perseverantes iconografias regionais. Sobre os ensejos que o levaram à produção do espetáculo, Carlos Eduardo Miranda tece as seguintes referências à música da região: “(...) tem a franqueza, o pé no chão, o quanto isso é expressivo desse povo, porque as aculturações sofridas foram bem traduzidas, como a influência da música caribenha, da música pop internacional, que quando chegou aqui se transformou em algo muito próprio, muito inédito. Acho que isso é muito especial..." (O LIBERAL, 28/02/2006,p 1).

12. A antropóloga Carmem Izabel Rodrigues acrescenta uma questão pertinente. A construção das identidades contemporâneas evidencia um paradoxo importante e necessário para que se compreenda as mais recentes estratégias de negociação identitária: “(...) enquanto os analistas sociais reconhecem que as identidades não são categorias ontológicas, essenciais ou primordiais, os grupos promovem, cada vez mais, a essencialização e a reificação das identidades, apresentando-as como fixas, primordiais, promovendo o retorno à etnia e exigindo o direito à diferença.” (RODRIGUES, 2006. p 120). Algo semelhante ocorre inclusive, quando o que está envolvido são as referências a alguma volatilidade identitária. Na medida em que se propõem legítimas, acabam por enfatizar a mesma fixidez associada às noções não-contigenciais de identidade.

13. Neste trabalho, utilizo das noções de performance e de drama a partir das aposições de Victor Turner (1979). Para o autor, mais do que um jogo de atividades articulado à vida cotidiana, a performance, por meio do drama, constitui um conjunto de expressões significativas que atua sobre a maneira com a qual a realidade é interpretada e concebida semanticamente - um processo dinâmico que combina e re-combina simbolicamente aspectos ou representações da sociedade, produzindo experiências capazes de estabelecer modificações ou sedimentações substanciais nas percepções dos indivíduos.

14. A biografia deste antropólogo é marcada pela contínua e deliberada afirmação da imagem de intelectual ao mesmo tempo pop, iconoclasta, cosmopolita e engajado. Sua trajetória remete aos anos 1980, quando ainda trabalhava como jornalista e se viu envolvido com a mediatização dos 
chamados bailes funk das periferias do Rio de Janeiro. De lá para cá, embora tenha adquirido grande influência nos domínios midiáticos mais hegemônicos, sua atuação, seja como produtor ou antropólogo, é notadamente apresentada como uma contínua cruqada em busca de expressões artísticas reconhecidas como periféricas e alheias aos grandes meios de comunicação.

15. Este caráter algo pioneiro que Hermano Vianna construiu por meio de sua biografia, como um desbravador musical, desde os tempos do funk carioca dos anos 1980, não se distancia muito do que o musicólogo cubano Leonardo Acosta apõe quando remete ao processo de colonização musical que marcou a relação entre as metrópoles europeias e suas colônias. A valorização do pitoresco pela Europa, a partir do século XVII, teria levado a uma busca estética pelo exótico, o que permitiu certa difusão, nas metrópoles, de elementos culturais oriundos das colônias: " $\mathrm{O}$ exotismo oferecia-se como um sonho tentador, tal como fora para os aventureiros do século dezesseis o ouro das índias” (ACOSTA. 1989 p 25). Nos meios artísticos europeus, a Espanha passou a ser percebida como a ponte entre o exotismo das colônias e o mundo metropolitano. $\mathrm{O}$ "espanholismo" e o "orientalismo" passaram a ordem do dia, em uma época na qual a França tornava-se a nação que descobria um mundo de sonoridades através de suas próprias fronteiras.

16. A ideia de extravagância não deixa de remeter, às avessas, ao caráter peculiar antes atribuído às expressões ditas folclóricas e, por conseguinte, autênticas, de que nos fala Renato Ortiz (2006).

17. Nesta mesma entrevista, Gaby Amarantos frisa ainda que, apesar da importância do festival para sua carreira, a grande mídia nunca deixou de ser um domínio a ser conquistado. O que se evidenciou na sua procura por produtoras e gravadoras renomadas do mainstream nacional. A projeção adquirida seria também resultado deste trabalho.

18. A ideia de metrópole só possui sentido se se considerar que as articulações identitárias aqui discutidas se dão no âmbito de uma relação caracteristicamente colonial do tipo centro/periferia, consoante o domínio relacional e constrastivo de que fala Frederik Barth (2011) e Cardoso de Oliveira (1976)

19. Embora as grandes narrativas comumente se apresentem como impositivas, observa-se que seu poder se situa mais no caráter hegemônico e legítimo de sua retórica do que na capacidade de não permitir interstícios ou de orientar e abarcar materialmente a dinâmica e a multiplicidade das relações sociais e simbólicas. Ou seja, as pessoas até reconhecem a autenticidade de tais narrativas, mas não necessariamente as reproduzem. Daí que a preponderância dos discursos em torno da condição fronteiriça e periférica paraense de modo algum levou ao arrefecimento de projetos artísticos mais ou menos indiferentes a este fenômeno (ainda que não se adequassem à proposta do Terruá Parâ). Bandas de rock, grupos de rap, dj's da eletrônica, conjuntos de jazz, dentre outros, não deixaram de empreender suas propostas independentemente da tendência majoritária.

20. A saber: Gaby Amarantos, Charme do Choro, Dona Onete, Sebastião Tapajós, Pio Lobato, Solano, Felipe e Manoel Cordeiro, Orquestra Jovem de Cellos da Amazônia, Paulo André Barata, Gang do Eletro, Carimbó Uirapuru de Marapanim, Edilson Moreno, Lia Sophia e Luê Soares.

21. Por sinal, foi na ocasião do segundo Terruá Pará que Nelson Motta pôde melhor conhecer esta nova cena, desde então se apresentando como mais um dos vários entusiastas e defensores. Não foram poucas as menções aos atributos especiais da música paraense propalada pelo produtor e jornalista, divulgando-a como a mais interessante, naquele momento. Tanto que em 2011 dedicou a coluna que mantém no Jornal da Globo à apresentação dos principais ritmos e artistas.

22. Apesar dos elogios, o declarado exclusivismo do segundo Terruá Pará recebeu críticas de alguns artistas e jornalistas, sobretudo pela ênfase arbitrária que reservou aos que mais se coadunavam às convergências mercadológicas e discursivas em voga. Houve críticas também à maneira como 
foram selecionadas as apresentações, cujo critério maior, segundo alguns entrevistados que, inclusive, participaram da produção do evento, seria o "humor" de Carlos Eduardo Miranda. De qualquer forma, possivelmente pelas críticas recebidas, em 2013 o Terruá Pará ampliou sua abarcabilidade com o lançamento da MostraTerruá Pará. O processo se deu por meio de um edital público que selecionou noventa propostas (dentre mais de trezentas). As apresentações ocorreram em um teatro da cidade, às terças-feiras, durante os meses de maio, junho e julho. No entanto, ironicamente, apenas doze atrações foram selecionadas para o TerruáPará principal. Destes, oito possuíam projetos com o tecnobrega e/ou com a guitarrada.

23. Neste mesmo ano, o respectivo projeto foi indicado ao Prêmio Bravo (bastante reconhecido no País) de melhor espetáculo.

\section{Referências bibliográficas}

ACOSTA, Leonardo. Música e descolonização. Lisboa: editorial caminho, 1989

ADORNO, Theodor W. O fetichismo na música e a regressão da audição. São Paulo: Nova Cultural. Os pensadores. 1996.pp 65-108

BARTH, Frederik. Os grupos étnicos e suas fronteiras. In Poutignat, Philipe e StreiffFenart, Jocelyne. Teorias da etnicidade: seguido de grupos étnicos e suas fronteiras de Frederik Barth. São Paulo: Ed Unesp. 2011

BENJAMIN, Walter. A obra de arte na época de sua reprodutibilidade técnica. In: ADORNO et al. Teoria da Cultura de Massa. São Paulo: Paz e Terra, 2000.

CARDOSO DE OLIVEIRA. Roberto. Identidade, etnia e estrutura social. São Paulo: Editora Pioneira, 1976

ESTADÃO. Artistas paraenses se apresentam no auditório Ibirapuera. São Paulo: Caderno 2-Música, 16/03/2006. Acessado em www.estadão.com.br

GOMES Fábio. Terruá Pará dá visibilidade nacional à música paraense. Belém: 01/07/2011. Acessado em www.paramusica.com.br

LEAL, Expedito. Rádio Repórter. O microfone aberto do passado. Belém: Meta Editorial e Propaganda. 2010

LIBERAL, O. Ritmos do Pará em Sampa - Gerações de artistas paraenses reúnem talentos em março no show 'Terroir Pará', no Parque Ibirapuera. Belém/Pa: 28/02/2006 (Cartaz)

MESSIAS, Ney. Quem apoia a indústria da música e do espetáculo no B r a s i 1 ? A c e s s a d o e m http://www.totemusicais.com.br/conteudo/leituras/default.php?id_leitura=46 em $27 / 04 / 2012$ 
MOTTA, Nelson. Ano de 2011 foi de ouro para a música brasileira. Rio de Janeiro: Jornal da Globo. Edição de 30/12/2011. Acessado em http://g1.globo.com/jornal-daglobo/noticia/2011/12/ano-de-2011-foi-de-ouro-para-musica-no-brasil.html

ORTIZ, Renato. Cultura brasileira e identidade nacional. São Paulo: Brasiliense. 2006

REVISTA TRIP. Gaby Amarantos - A Garota da periferia de Belém que está decidida a ganhar o mundo sem sair do seu bairro. 19/12/2011 (por Ariane Abdallah)

RODRIGUES, Carmem Izabel. Caboclos na Amazônia: A identidade na diferença. Belém/Pa: Novos cadernos NAEA. v. 9, n. 1,p. 119-130, jun. 2006

SAHLINS, Marshall. Metáforas Históricas e Realidades Míticas. Rio de Janeiro: Zahar. 2008

TAVARES. Luís Felipe. Terruá Pará 2011.Festival reúne em São Paulo o que há de melhor na música paraense em 2011. São Paulo: 21/06/2011. Acessado em http://revistatrip.uol.com.br/trip/terrua-para-2011

TURNER, Victor. Process, Performance and Pilgrimage. A Study in Comparative Simbology. New Delhi: Concept Publishing Company New Delhi,1979.

VIANNA, Hermano. A música paralela: Tecno-brega consolida nova cadeia produtiva, amparada em bailes de periferia, produção de CDs piratas e divulgação feita por camelôs. São Paulo: A Folha de São Paulo, Caderno C, p. A3, 13/10/2003.

VIANNA, Hermano. Isso é Calypso ou a Lua não me traiu. Rio de Janeiro: O ve rm un d o. $17 / 07 / 2007$. A c e s s a d o e m http://www.overmundo.com.br/perfil_favoritas/oona-castro 